\title{
Colorectal Cancer in UAE, Implications on the Screening Program 2018
}

\author{
Makki H Fayadh* and Salem Awadh Sabih \\ London Consultant Physician \& Gastroenterologist, MRCP, UK
}

Received: 䠊 June 25, 2018; Published: 眥 July 03, 2018

*Corresponding author: Makki H Fayadh, FRCP ED, FRCP London Consultant Physician \& Gastroenterologist, MRCP UK

\section{Abstract \\ Introduction}

a) Colorectal cancer is the fourth $\left(4^{\text {th }}\right)$ common cancer in both sexes, worldwide and is the third most common cancer in men and the second in women.

b) In 2012, 1.36 million cases of colorectal cancer occurred and there were 693,881 deaths

c) The incidence is increasing under age 50 and it is the second killer cancer in UAE in 2017 [1].

d) According to health authority of Abu Dhabi( HAAD) in a report published in 2012 colon cancer is the $2^{\text {nd }}$ common cancer and $4^{\text {th }}$ common cause of cancer deaths in men and $3^{\text {rd }}$ most common cancer and $2^{\text {nd }}$ common cause of cancer deaths in women.(www.haad.ae)

e) In UAE the data showed average age for colorectal cancer to be 51 years, $59 \%$ were men and $41 \%$ were women [2].

f) In the Emirate of Abu Dhabi the Health Authority of Abu Dhabi (HAAD) instituted 2013 a colon cancer prevention program including primary preventive strategies by education, weight control\& exercise and secondary prevention strategies by either colonoscopy or fecal immune testing starting at age 40-75.

g) The campaign was designed to coincide with the global awareness months in march that are assigned for colorectal cancer [3].

\section{Outcome Study-2012-2018 (Single Center Experience ACDS) 6078 Colonoscopies}

a) 6078 colonoscopies performed for multiple indications, 1554 Colon Polyps were detected 22\%.

b) 58 cancers were detected during this period $1.1 \%$ [4-6].

c) Age range 29-81 years, $41 \%$ below 50 years, 22\% below age 40 .

\section{Conclusion}

a) Our single center (ACDS) data of 6078 colonoscopies done for a variety of indications showed $22 \%$ colon polyps \& $1.1 \%$ colorectal cancers

b) $\quad 58$ cancers detected $40 \%$ below age $50,22 \%$ below age 40 .

c) Colorectal cancer affect younger populations.

d) The implication for the screening program is to review the screening age and possibly starting at younger ages.

e) More data from different centers needed to evaluate the age of colorectal cancer screening.

Keywords: Colorectal cancer, Colon polyps, Colorectal cancer screening in UAE 


\section{Introduction}

i. Colorectal cancer is the fourth $\left(4^{\text {th }}\right)$ common cancer in both sexes, worldwide and is the third most common cancer in men and the second in women $[6,7]$.

ii. In 2012, 1.36 million cases of colorectal cancer occurred and there were 693,881 deaths

iii. The incidence is increasing under age 50 and it is the second killer cancer in UAE in 2017.

iv. In the Emirate of Abu Dhabi the Health Authority of Abu Dhabi (HAAD) instituted 2013 a colon cancer screening program.

v. According to HAAD in a report published in 2012 colon cancer is the $2^{\text {nd }}$ common cancer and $4^{\text {th }}$ common cause of cancer deaths in men and $3^{\text {rd }}$ most common cancer and $2^{\text {nd }}$ common cause of cancer deaths in women.

vi. HAAD colon cancer prevention program included primary preventive strategies and secondary prevention by stool fit test every 2 years or colonoscopy every 10 years [8-11].

vii. Colorectal cancer risk factors in Abu Dhabi:

viii. Non-modifiable risk factors included:

a. Family history of colorectal cancer,

b. Personal history of colorectal cancer,

c. Personal history of polyps in the colon, ulcerative colitis or Crohn's Disease,

d. Age older than 40 years,

\section{Modifiable Risk Factors Include}

i. Obesity,

ii. A diet high in fat and red meat and low in fruits and vegetables,

iii. Low levels of physical activity (sedentary lifestyle),

iv. Tobacco use (cigarettes, shisha and medwakh, etc.),

v. Alcohol consumption,

vi. In 2017: The Health Authority of Abu Dhabi (HAAD), revealed that the majority $63 \%$ of colorectal cancer cases are detected at a late stage and $90 \%$ of colorectal cancer can be successfully cured if the disease is detected early.

vii. HAAD recommends screening for colorectal cancer for men and women 40-75

viii. Fecal exam once every 2 years or by Colonoscopy once every 10 years. ix. Regular screening can prevent development of colorectal cancer through the detection and removal of pre-cancerous lesions [12].

$\mathrm{x}$. The risk of developing colorectal cancer increases with age.

xi. Medical conditions such as colorectal polyps or inflammatory bowel disease increase the risk of developing colorectal cancer.

xii. Genetic factors also play a role.

xiii. A family history of colorectal cancer or other related genetic syndromes increase the risk of developing the disease.

xiv. HAAD's statistics revealed that the early detection program contributed to the early diagnosis of $37 \%$ (stage 0 or in situ: $6.7 \%$, stage I: $21.3 \%$, and stage II: $8.9 \%$ ) from all diagnosed and staged colorectal cancer cases while $63 \%$ of were detected in their later stages.

xv. HAAD urges all members of the community who wish to take colorectal cancer screening tests to visit any of the 27 health facilities offering them throughout the Emirate of $\mathrm{Abu}$ Dhabi.

xvi. Patients are recommended to use online appointments through www.haad.ae/simplycheck/appointment

xvii. "Colorectal cancer doesn't display any symptoms in its early stages, and so regular screenings contribute to saving many lives.

xviii. Undergoing periodic preventive tests helps to eradicate and remove polyps in the colon or rectum before they become cancerous.

xix. The tests also help to detect tumors at an early stage, which increases the chances of successful treatment and minimizes medical intervention".

xx. Symptoms of colorectal cancer don't appear until a later stage [13].

xxi. These symptoms include; rectal bleeding or blood in the stool, a change in normal bowel movements (diarrhoea, constipation or both for more than 2 weeks), abdominal pain and unexplained weight loss or anaemia.

xxii. HAAD's efforts come in line with its cancer awareness campaign launched in October 2016 for a period of six months through March 2017, under the slogan "Live Healthily and Simply Check".

xxiii. The campaign was designed to coincide with the global awareness months that are assigned for each respective disease: October for breast cancer, November for lung cancer, 
January for cervical cancer and March for colorectal cancer. For cancer screening appointments and all campaign information, please visit www.haad.ae/simplycheck.

xxiv. Risk stratification for CRC.

xxv. High risk.

xxvi. $100 \%$ Presence of familial adenomatous polyposis.

xxvii.80\%Presence of hereditary nonpolyposis colorectal cancer.

xxviii. Moderate risk.

xxix. 20\%Presence of chronic colitis due to ulcerative colitis or Crohn's colitis.

xxx. 10-20\% Familial: First-degree relative with colorectal cancer.

xxxi. Average risk (negative family history).

xxxii. $5-6 \%<50$ years of age.

xxxiii. Available genetic tests for the patient or her affected family member(s) that may be recommended by the Cancer Genetics professional based on the assessment.

a) Outcome (Single Center Experience) ACDS 2013-2018 Data was extracted from 6078 colonoscopies performed at Advanced Center for Daycare Surgery ( ACDS) over a 6 year time frame $[14,15]$.

b) 1554 Colon Polyps were detected $22 \%$.

c) 58 cancers were detected during this period.

d) Age range 29-79 years.

e) $41 \%$ below 50 years.

f) $22 \%$ below age 40 .

g) Age range 29-79 years.

\section{Conclusion}

a) Our data from 6078 colonoscopies showed a prevalence rate of polyps $22 \%$ \& 58 cancers seen during this period with average age of colon cancer of 54 years.

b) $41 \%$ of cancers below age 50 .

c) More multi center studies are needed to understand the burden of disease that colon cancer presents in the Emirate of Abu Dhabi [16].

\section{References}

1. Imperiale TF, Glowinski EA, Lin Cooper C, Gregory N Larkin, James D Rogge, et al. (2008) Five-year risk of colorectal neoplasia after negative screening colonoscopy. N Engl J Med 359: 1218-1224.

2. Winawer SJ, Zauber AG, Ho MN, O Brien MJ, Gottlieb LS, et al. (1993) The National Polyp Study Workgroup. Prevention of colorectal cancer by colonoscopic polypectomy. New Engl J Med 329(27): 1977-1981.

3. Hassan C, Pickhardt PJ, Rex DK (2010) A resect and discard strategy would improve cost-effectiveness of colorectal cancer screening. Clin Gastroenterol Hepatol 8(10): 865-869.

4. Ignjatovic A, East JE, Suzuki N, Vance M, Guenther T, et al. (2009) Optical diagnosis of small colorectal polyps at routine colonoscopy (Detect Inspect Characterise Resect and Discard; DISCARD trial): a prospective cohort study. Lancet Oncol 10(12): 1171-1178.

5. Brown SR, Baraza W, Din S, Riley S (2010) Chromoscopy versus conventional endoscopy for the detection of polyps in the colon and rectum. Cochrane Database Syst Rev 4: CD006439.

6. Wallace MB, Kiesslich R (2010) Advances in endoscopic imaging of colorectal neoplasia. Gastroenterology 138(6): 2140-2150.

7. van den Broek FJ, Reitsma JB, Curvers WL, Fockens P, Dekker E (2009) et al. Systematic review of narrow-band imaging for the detection and differentiation of neoplastic and nonneoplastic lesions in the colon (with videos). Gastrointest Endosc 69: 124-135.

8. Sonwalkar S, Rotimi O, Rembacken BJ (2006) Characterization of colonic polyps at conventional (nonmagnifying) colonoscopy after spraying with $0.2 \%$ indigo carminedye. Endoscopy 38(12): 1218-1223.

9. Jemal A, Bray F, Center MM, Ferlay J, Ward E, et al. (2011) Global cancer statistics. CA Cancer J Clin 61(2): 69-90.

10. Siegel R, Naishadham D, Jemal A (2018) Cancer statistics. CA Cancer J Clin 68(1): 7-30.

11. Kohler BA, Ward E, Mc Carthy BJ, Schymura MJ, Ries LA, et al. (2011) Annual report to the nation on the status of cancer, 1975-2007, featuring tumors of the brain and other nervous system. J Natl Cancer Inst 103(9): 714-736.

12. (2011) Centers for Disease Control and Prevention (CDC). Vital signs: Colorectal cancer screening, incidence, and mortality--United States, 2002-2010. MMWR Morb Mortal Wkly Rep 60: 884.

13. Edwards BK, Ward E, Kohler BA, Eheman C, Zauber AG, et al. (2010) Annual report to the nation on the status of cancer, 1975-2006, featuring colorectal cancer trends and impact of interventions (risk factors, screening, and treatment) to reduce future rates. Cancer 116(3): 544573.

14. (2008) Centers for Disease Control and Prevention (CDC). Use of colorectal cancer tests--United States, 2002, 2004, and 2006. MMWR Morb Mortal Wkly Rep 57: 253.

15. Meissner HI, Breen N, Klabunde CN, Vernon SW (2006) Patterns of colorectal cancer screening uptake among men and women in the United States. Cancer Epidemiol Biomarkers Prev 15(2): 389-394.

16. Henley SJ, King JB, German RR, Richardson LC, Plescia M, et al. (2010) Surveillance of screening-detected cancers (colon and rectum, breast, and cervix)-United States, 2004-2006. MMWR Surveill Summ 59(9): $1-25$. 


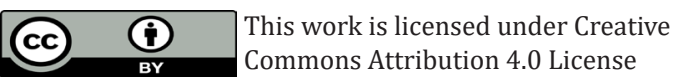

To Submit Your Article Click Here: $\quad$ Submit Article

DOI: $10.32474 /$ OAJOM.2018.02.000135

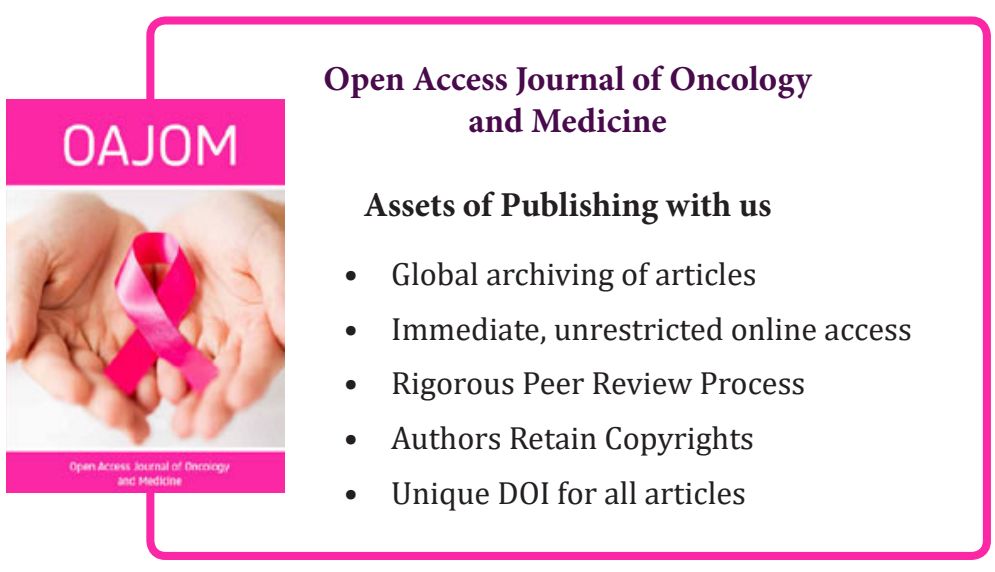

